\title{
Design and Fabrication of Automated Work Piece Counting and Sorting using Image Processing
}

\author{
Dhanasekar. J, Sengottuvel. P, Priya V
}

\begin{abstract}
In that logical decision, controls is of two types and are microcontroller and PLC (programmable logical control) .PLC based and microcontroller control based systems are used for automation process for in industries. Since automation is very important for an industry to reduce human effort this project is been developed.In this project a system is been implemented for automated work piece counting and rejection that works using microcontroller linked with image processing concept. These kinds of system are mainly used in Quality Control department to remove scraps. This system is built using Arduino controller and the basic concepts of image processing using MATLAB .The rejected materials are collected in separate bins and are removed as scraps.
\end{abstract}

Keywords: Workpiece counting and Sorting , Arduino, image Processing, MATLAB

\section{INTRODUCTION EMBEDDED SYSTEM}

As the name means, an inserted framework is implanted/Assembled or incorporates with something different. Implanted frameworks envelop an assortment of equipment and programming parts, which perform explicit capacities in host framework, for instance Washing machine, handheld phones and vehicles and so on. Implanted frameworks have turned out to be expanding advanced and furthermore with a non-computerized fringe (simple power) and here and there both framework. The main advantage of Embedded system are user compatibility to develop their own controllers that run based on the coding developed by them. Most embedded control product had special requirement, cost effectiveness, low power, small-footprint and a high level of system integration. [1],[3],[5]

Ordinarily, most inserted control frameworks are control framework, that are planned around a MCU, which incorporates on-chip program memory, information memory (RAM) and different fringe capacities, similar to clock and sequential and parallel correspondence among gadgets . What's more, these frameworks ordinarily require simple/interface gadgets, sequential EEPROM show driver's keypads or little shows to store the pattern of information in this manner to execute the application.

Revised Manuscript Received on August 22, 2019.

J.Dhanasekar,, Department of Mechatronics ,Bharath Institute of Higher Education \& Research,TamilNAdu Email: Jdhanasekar81@gmail.com

Sengottuvel. P Department of Mechatronics ,Bharath Institute of Higher Education \& Research, TamilNAdu Email: hodmechatronics@bharathuniv.ac.in

Priya.V, Department of Mechatronics ,Bharath Institute of Higher Education \& Research,TamilNAdu Email: priyaygna14@gmail.com

\section{EMBEDDED SOFTWARE}

Programming in the installed framework can be embedded with either low level computing construct or any abnormal state language. Low level computing construct are of troublesome in nature to execute a monotonous application. Thus Now-a-days $\mathrm{C}$ and $\mathrm{C}++$ has been the decision ,yet dialects are decide for the installed programming is for the accompanying reasons.

* $\mathrm{C}$ and $\mathrm{C}++$ are machine autonomous language, so the software engineer can focus just on the calculations constructed or created by him and they are the simplest one to actualize the created calculations.

* C has the capacity for direct equipment control utilizing microcontrollers and it tends to be interfaced to run any mechanical machine.

Any source code written in $\mathrm{C}$ and $\mathrm{C}++$ or low level computing construct must be changed over into an executable picture that can be stacked onto an EEPROM chip utilizing consuming units or utilizing code change utilizing Bluetooth gadgets. The way toward changing over the source code portrayal of inserted programming into an executable picture includes three unmistakable advances and the framework or PC on which these procedures are executed is called have PC. [2 ],[4],[6]

There are a few contrasts between customary programming and implanted programming. Regardless of whether the processor design is the equivalent, the I/O interfaces or sensors or activators may contrast. Second, there is a distinction in the improvement and investigating of Programs/Applications. The Embedded framework programming contain building program that will keep running on the host. These instruments are called Native devices. [7],[9], [10]

\section{MECHANICAL DESIGN}

Two conveyor system arrangements are built. The top conveyor is used to make the work piece to get loaded and the second one foe collecting the sorted work piece .The work piece will be loaded one after another with the same interval limit. Two IR sensors are used to locate the object in the conveyor system to ensure the availability of the work piece. A camera is placed on the top to capture the image of the work piece. An ejector is been placed operated by a DC motor controlled by a driver module to eject the sorted work piece.

On the second conveyor system different bins are kept equal distance to collect the sorted work

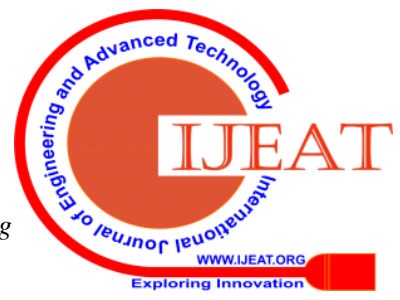




\section{Design and Fabrication of Automated Work Piece Counting and Sorting using Image Processing}

piece. The mechanical design is represented in the following figure 1 .

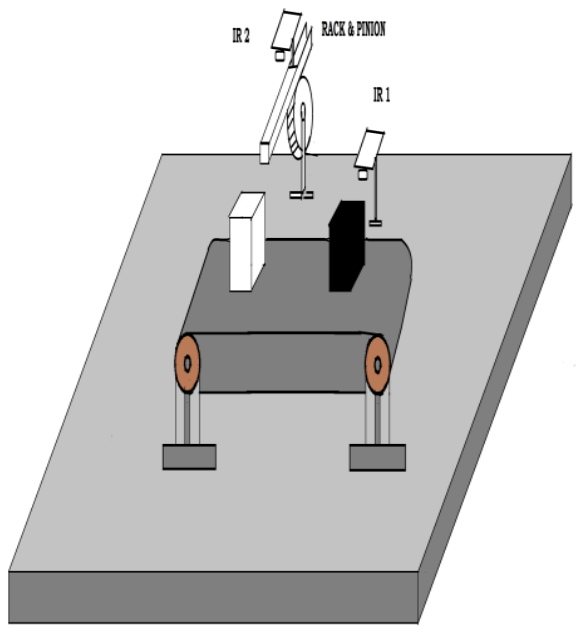

Figure1.Mechanical design

\section{BLOCK DIAGRAM}

The following block diagram describes the working of the system.

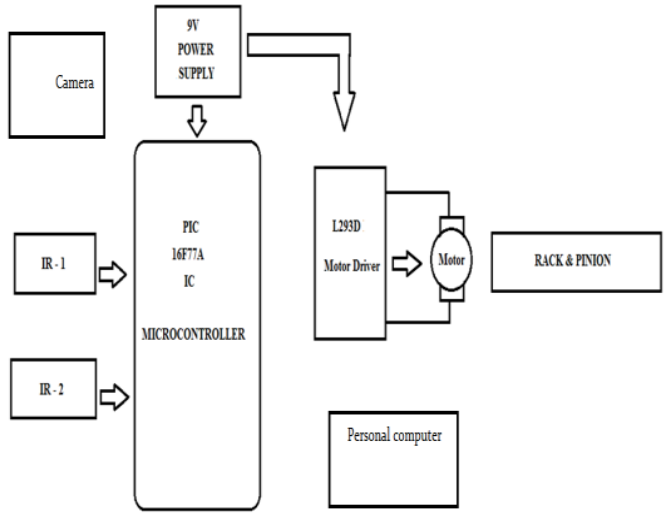

The image will be captured using the camera and is fed to the $\mathrm{PC}$ where software is running. Based on the coding developed the captured image will be categorized and the feed back signal will be fed to the microcontroller. The motor driver IC will activate the motor to rotate the rack and pinion arrangement to eject the sorted work piece in to the bin. The conveyors are rotated at constant speed to load the work piece as well as to collect the workpiece. [14],[16], [18]

\section{A. COMPONENENTS USED}

AARDUINOUNOR3supervisor with choices like punctuation feature, support coordinating, and programmed space, and is furthermore fit for aggregation and transferring projects to the board with a single tick. A program or code composed for Arduino is named a "sketch".

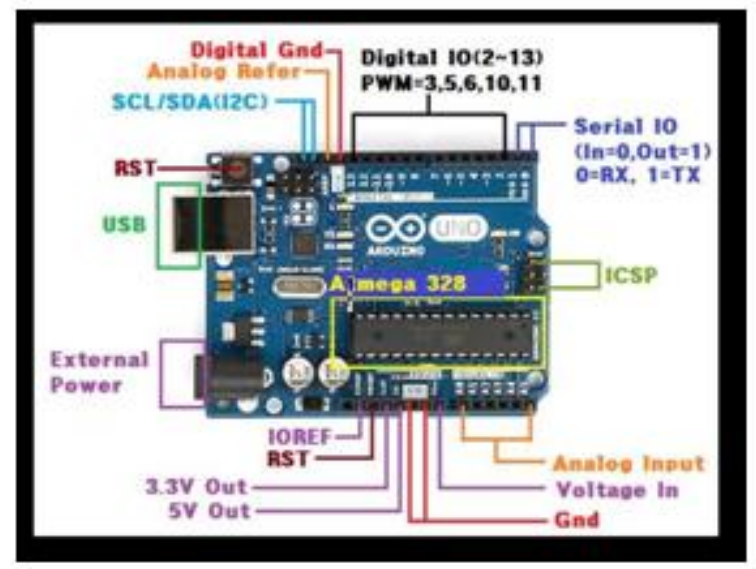

B. MATLAB

Matlab (Matrix research center) is an intuitive programming framework for numerical calculations and designs. As the name proposes, Matlab is particularly intended for lattice calculations: fathoming frameworks of straight conditions, registering eigenvalues and eigenvectors, figuring grids, etc. What's more, it has an assortment of graphical capacities, and can be reached out through projects written in its very own programming language. Numerous such projects accompany the framework; some of these stretch out Matlab's capacities to nonlinear issues, for example, the arrangement of introductory worth issues for normal differential conditions. The fundamental information type in Matlab is a n-dimensional exhibit of twofold accuracy numbers.

\section{L293D MOTOR DRIVER IC}

The L293D engine driver ICs ar fourfold high-ebb and flow [*fr1] H drivers. The L293D engine driver IC is intended to supply bifacial drive flows of up to 600MA at voltages from four.5V to $36 \mathrm{~V}$. The L293D engine driver IC are intended to drive inductive masses like transfers, solenoids, dc and bipolar venturing engines, further as elective high-ebb and flow/high voltage masses in positive-supply applications.

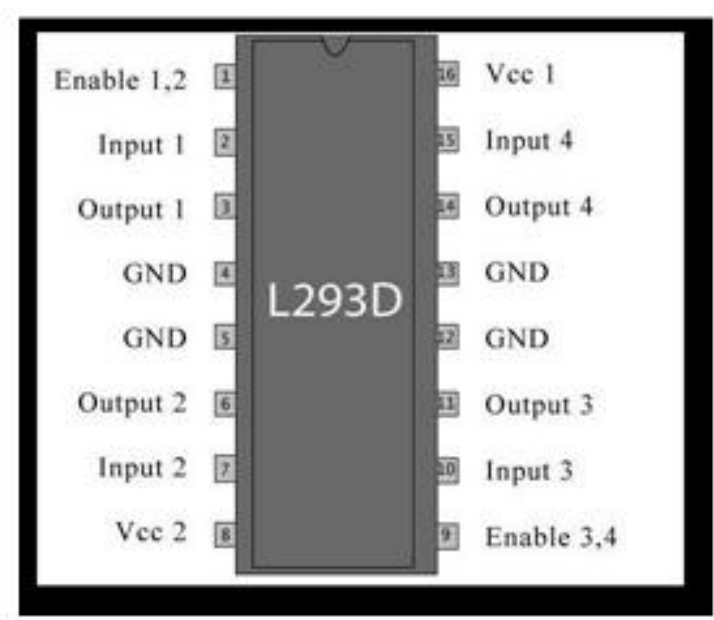


(1)

\section{WORKING CONCEPT}

The Work pieces will be loaded through a pipe line closed at regular intervals of time using a shutter at the end of the pipe. This arrangement will locate the work piece on the conveyer. The conveyer is designed top run continuously at constant speed to move the work piece. IR sensor will sense the work piece and give the pulse signal to the microcontroller as 1 to ensure the availability of object and also to have a count .The counter program has been programmed to the controller and an LCD is interfaced with controller as per the circuit diagram to show the no.counts of the workpiece. Once the signal from the controller ensures the object the camera captures the image and the corresponding signal is evoked by the controller.

The image will be transferred to the PC where MATLAB programming is running. The coding is been developed on the basis of image processing. The pixels of the work piece is compared with the already stored and if ti matches a high signal corresponding to the specified colour will be sent to the controller.

The controller transfer the command to the DC motor linked with rack and pinion arrangement to run at a apecified speed. Hence the workpiece will be ejected into the corresponding bin assigned to collect the workpiece .If no three colours like red ,green, blue colour worrkpiece is not there then it will be ejected into the foutrth bin to collect the scrap.

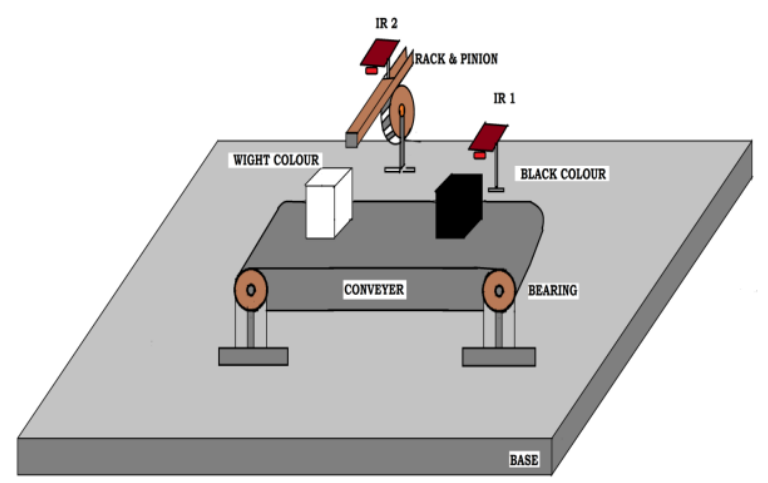

Figure3.Working Project

\section{RESULT AND CONCLUSION}

In this paper a new rejection method instead of pneumatic system is proposed to sort the workpieces. This technology is very useful for industry where batch production of minimum three coloured objects s been produced. This type of system is implemented for mass production job in a company, it reduces human effort to sort and count the workpiece and also reduces man power.

\section{REFERENCES}

1. Dhanasekar, J., Sengottuvel, P. \& Palanikumar, K. 2019, "Implementation of effective fuel saving methodology for turbines using air drag in vehicles", Materials Today: Proceedings, pp. 421

2. Kumar, S.S., Kumar, K.S.R. \& Kumar, N. 2018, "Experimental evaluation of magnetorheological damper characteristics for vibration analysis", International Journal of Vehicle Structures and Systems, vol. 10, no. 1, pp. 30-34.

3. Dhamodaran, K., Adikesavana, P., Shankar, P.P. \& Gowtham, S. 2018 "Conceptual development of flapping wing for unmanned aerial vehicles: Technical note", International Journal of Vehicle Structures and Systems, vol. 10, no. 1, pp. 43-45.

4. Karthikeyan, S., Raman Balasubramanian, S.R., Ramesh, B., Raghul, S. \& Sathish Kumar, S. 2019, "The automatic solar tracker chronicles", International Journal of Recent Technology and Engineering, vol. 8, no. 1, pp. 312-315.

5. Hema, R., Sundararajan, M. \& Balaji, S. 2019, "Smartphone control robot with automatic firing gun", International Journal of Innovative Technology and Exploring Engineering, vol. 8, no. 9 Special Issue 3, pp. 625-627.

6. Balambica, V., Deepak, V. \& Kumar, S. 2019, "Design and efficiency of an asymmetric gear", International Journal of Mechanical and Production Engineering Research and Development, vol. 9, no. 3, pp. 223-230.

7. Saravana, S., Balaji, S., Arulselvi, S. \& John Paul Praveen, A. 2019 "Reliable power quality monitoring and protection system", International Journal of Innovative Technology and Exploring Engineering, vol. 8, no. 9 Special Issue 3, pp. 644-645.

8. Bycil, V.J. \& Wiselin, M.C.J. 2019, "Modeling and analysis of vibration energy harvesting system using piezo stack", International Journal of Mechanical and Production Engineering Research and Development, vol. 9, no. Special Issue 1, pp. 523-533.

9. Sripada, A., Warrier, A., Kapoor, A., Gaur, H. \& Hemalatha, B. 2018 , "Dynamic lateral balance of humanoid robots on unstable surfaces", International Conference on Electrical, Electronics, Communication Computer Technologies and Optimization Techniques, ICEECCOT 2017, pp. 539.

10. Mahalakshmi, V. \& Vijayaragavan, S.P. 2019, "PV based power electronic converters for high voltage DC applications", International Journal of Recent Technology and Engineering, vol. 7, no. 6, pp. 670-674.

\section{AUTHORS PROFILE}

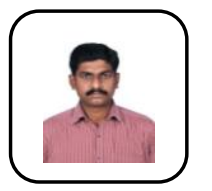

J.Dhanasekar, Assistant Professor,Department of Mechatronics Bharath Institute of Higher Education \& Research,TamilNAdu

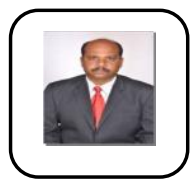

Sengottuvel. P, Professor,Department of Mechatronics Bharath Institute of Higher Education \& Research,TamilNAdu

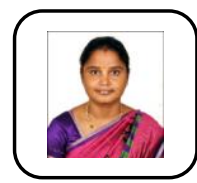

Priya.V, Assistant Professor,Department of Mechatronics Bharath Institute of Higher Education \& Research,TamilNAdu 